\title{
Status of Adolescent Sexual and Reproductive Health in Nepal
}

\author{
Pitambar Acharya, \\ bnjskt.pitambar@gmail.com \\ Lecturer \\ Central Department of Education, T.U., Kirtipur \\ Gita Rijal, MPhil Scholar \\ gita.rijal2071@gmail.com
}

\begin{abstract}
Adolescence is the transitional stage (10-19 years) of physical and psychological development that occurs during the period from puberty to adulthood. Adolescent and Sexual Reproductive Health (ASRH) is a healthy condition concerning the system, function and reproductive processes owned by a teenager. ASRH had been taken as an important issue after 1994 International Conference on Population and Development (ICPD)which took it as key issue. The main objective of this article is to analyse the general status of ASRH based on the information from Nepal Demographic and health survey 2016 thematically with descriptive design. Marriage, sexual relationship, fertility, knowledge and use of family planning, maternal and child health, knowledge on abortion, physical and sexual violence in terms of ASRH. Besides, policy intervention, gaps and recommendations have also been discussed briefly.
\end{abstract}

Keywords: Adolescent, maternal child health, sexual health, reproductive health, violence

\section{Introduction}

Adolescence is the period of transition from childhood to adulthood. In this stage, various physical and psychological developments occur. It is also the transition period from puberty to legal adulthood. UNFPA and UN define adolescents as the 10-19 year olds (early adolescence 10-14; late adolescence 15-19), youth: 15-24 year olds, and young people: 10-24 year olds (MOPE, 2016).

Sexual and reproductive health (SRH) is a state of complete physical, mental and social wellbeing in all matters relating to the reproductive system. It implies that people are able to have a satisfying and safe sex life, the capability to reproduce, and the freedom to decide if, when, and how often to do soUNFPA (n. d.). Sexual and reproductive health rights (SRHRs) are human rights. The right to sexual and reproductive health implies that people are able to enjoy a mutually satisfying and safe relationship, free from coercion or violence and without fear of infection or pregnancy, and that they are able to regulate their fertility without adverse or dangerous consequences(IPPF, 2011). Adolescent sexual and reproductive health (ASRH) is a healthy state in terms of the system, function and reproductive processes of a teenager. 
Specially, ASRH had been taken as the current issue after 1994 International Conference on Population and Development (ICPD) has been marked as the key event for reproductive health. The ICPD emphasized the issue of reproductive health service for women which included safe motherhood services, prevention and treatment of HIV and AIDS, post-abortion care services, prevention and treatment of infertility, newborn care, adolescent $\mathrm{RH}$ and the elderly $\mathrm{RH}$ as a holistic issue in term of life cycle approach and emphasized that $\mathrm{RH}$ as a central to the agenda of human rights. Finally, gender-based violence had also been incorporated in RH (Lamichhane, 2019). Within this context, the main objective of this article is to analyse the general situation of adolescent sexual and reproductive health based on the information from Nepal Demographic and health survey 2016. Therefore, "What is the situation of adolescent sexual and reproductive health in Nepal?" is the main research question of this article. This article is informative for the students and research scholars in the concerned field.

\section{Methodology}

This article is in descriptive design based on secondary sources mainly from 2016 Nepal Demographic and Health Survey. ASRH related information from NDH 2016 were used for further analysis to describe the situation of ASRH thematically. Besides, other national publications as well as the international publications of WHO, UN, UNFPA have been reviewed for the discussion of the themes.

\section{Result and Discussion}

Adolescent reproductive health is still a current issue in terms of human right. Globally, 750 million women and girls were married before the age of 18 and at least 200 million women and girls in 30 countries have undergone FGM (UN, n. d.). Globally, adolescents (age 1019) account for nearly one-fifth (18 percent) of the total population (UN, 2011.) In Nepal, adolescents comprise about one-fourth of the national population (MoHP, 2011). The practice of early marriage is common and is deeply rooted in the culture (though the legal minimum age at marriage in Nepal is 20 years as per the National Civil (Code) Act, 2017 (2074).Early marriage and resulting early sexual debut can lead to a number of potentially adverse outcomes, including unplanned pregnancy and exposure to sexually transmitted infections (STIs) (WHO, 2011). Besides, it can lead the dropout from formal education at high school and higher level, especially for girls.

\section{Adolescents and sexual relationship}

In terms of sexual relationship, 2016 NDHS has mentioned, out of the total female of 15-19 years never married were 72.5 percent, married 27.1 percent, Separated 0.2 percent whereas out of total male, of 15-19 years never married were 93.2 percent, married 6.2 percent, and Separated 0.0 percent and. Similarly, median age at first marriage for female(of current age 25-49) was 17.9 years whereas median age at first marriage for male (of current age 25-49) was 21.7 years. Besides, age at

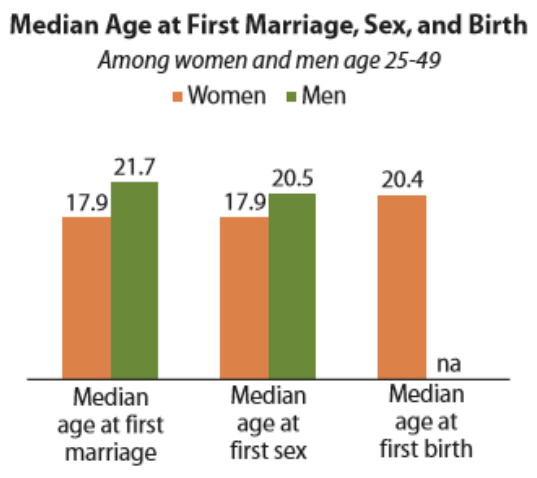

Source: 2016 NDHS Report 
first sexual intercourse female (of current age 25-49) was 17.9 years whereas median age at first sexual intercourse male (of current age 25-49) was 20.5 years (MOH, Nepal, New ERA\& ICF, 2017).

\section{Adolescents and fertility}

According to 2016 NDHS, 27.1 percent of female of age 15-19 and 6.4 percent of male of age 15-19 are currently in a union. In Nepal, 17 percent of women age 15-19 had begun child bearing, 13 percent had had a live birth and 4 percent are pregnant with their first child. Age specific fertility rate (ASFR) for $15-19$ years was 88 per 1000 women. This value was 66 for urban and 125 rural adolescents (MOH, Nepal, New ERA \& ICF, 2017). Adolescent fertility is not only important from a demographic perspective, it is also a concern of human rights and health issue as it is associated with negative outcomes for maternal and child health(Diaz \& Fiel, 2016; Mollborn, 2017, cited in Gabett, Perilli-Harris, \& Neal, 2021). Besides, it also hampers the opportunity of education and economic development. This also fact justifies the reproductive health services to avoid the adolescent fertility.

\section{Adolescents and family planning: Knowledge and use}

As per the 2016 NDHS, there was the higher knowledge to adolescents of 15-19 than 10-15. Highest share of respondents had heard about condom followed by injectable. The knowledge of family planning was higher among female in comparison to male $(\mathrm{MoH}, \mathrm{Nepal}$, New ERA \& ICF, 2017). This can be shown in the following table:

Table 1. Adolescents' knowledge on family planning, 2016

\begin{tabular}{|l|l|l|l|l|l|l|l|l|l|}
\hline & Condom & Pills & Injectable & $\begin{array}{l}\text { Female } \\
\text { sterilization }\end{array}$ & $\begin{array}{l}\text { Male } \\
\text { sterilization }\end{array}$ & E. pills & Withdrawal & Others & N \\
\hline $10-15$ & 94.19 & 62.7 & 74.38 & 43.99 & 37.66 & 5.11 & 0.77 & 8.18 & 1334 \\
\hline $15-19$ & 96.5 & 84.63 & 88.21 & 68.84 & 65.30 & 17.65 & 9.22 & 21.88 & 2317 \\
\hline
\end{tabular}

Knowledge of adolescents (male) on family planning, 2016

\begin{tabular}{|l|l|l|l|l|l|l|l|l|l|}
\hline & Condom & Pills & Injectable & $\begin{array}{l}\text { Female } \\
\text { sterilization }\end{array}$ & $\begin{array}{l}\text { Male } \\
\text { sterilization }\end{array}$ & $\begin{array}{l}\text { E. } \\
\text { pills }\end{array}$ & Withdrawal & Others & N \\
\hline $10-15$ & 98.86 & 47.89 & 54.84 & 48.37 & 39.73 & 7.77 & 4.15 & 8.94 & 1732 \\
\hline $15-19$ & 98.51 & 76.73 & 76.34 & 71.80 & 66.54 & 23.75 & 22.13 & 20.80 & 2153 \\
\hline
\end{tabular}

Source: 2016 NDHS

Note: The term 'E. Pills' denote 'Emergency pills'.

In terms of use of family planning method, out of 704 married female of age 15-19, 23.1 percent had used any method of family planning. Out of them, 14.5 percent were using any modern method and 8.6 percent were using any traditional method. Among them, 5.5 percent were using injectable, 4.4 percent were using male condom, 2.2 percent were using pill, and 2.1 percent were using implants. IUD was less popular than others were because just 0.2 percent was using 
it. About 77 percent of the adolescents were not using any methods (MOH, Nepal, New ERA \& ICF, 2017).

This poor use of the methods can be because physical access to health services may be problematic for some adolescents (Pandey, Seale \& Razee, 2019). Therefore, the government must ensure the access of reproductive health service and such services must be adolescent-friendly.

\section{Maternal and child health}

About a half $(48.5 \%)$ of the women under 20 years had delivered their birth in government sector health facility, whereas about 35 percent delivered at home. In total (including private sector), 63.7 percent of them had delivered in a health facility (MOH, Nepal, New ERA \& ICF, 2017).

Not only the women but also the mortality of children is affected by the age of mother. The mortality was found highest for the mother of age less than 20 at the age of birth (MOH, Nepal, New ERA \& ICF, 2017). It has been shown in the following table:

Table 2 :Neonatal, post-neonatal, infant and under-5 mortality rates for the $\mathbf{1 0}$-year period preceding the survey by mothers age at birth, Nepal DHS 2016

\begin{tabular}{|l|l|l|l|l|}
\hline $\begin{array}{l}\text { Mother's age at } \\
\text { birth }\end{array}$ & $\begin{array}{l}\text { Neonatal } \\
\text { mortality }\end{array}$ & $\begin{array}{l}\text { Post-neonatal } \\
\text { mortality }\end{array}$ & Infant mortality & $\begin{array}{l}\text { Under-five } \\
\text { mortality }\end{array}$ \\
\hline Less than 20 & 39 & 15 & 54 & 61 \\
\hline $20-29$ & 21 & 12 & 33 & 40 \\
\hline $30-39$ & 31 & 11 & 42 & 48 \\
\hline Total (Nepal) & 21 & 12 & 32 & 39 \\
\hline
\end{tabular}

Source: 2016 NDHS

Maternal mortality is 239 per 100000 live births in Nepal according to NDHS 2016. Percentage of female deaths that are maternal for the age 15-19 was 7.5 percent (MOH, Nepal, New ERA \& ICF, 2017).

\section{Maternal mortality of age 15-19}

Based on the direct estimates of maternal mortality rates for the 7 years preceding the survey, by 5-year age groups, there was maternal mortality ratio of 239 per 100000 in NDHS 2016. Similarly, 7.5 percent of female of age 15-19 had died due to maternal causes (MOH, Nepal, New ERA \& ICF, 2017). This value is very high in comparison to developed countries.

\section{Knowledge on legality of abortion}

The adolescent girls also face unwanted pregnancy. However, only 41 percent of the women 15-19 years thought that abortion is legal in Nepal according to 2016 Nepal Demographic and Health Survey (MOH, Nepal, New ERA \& ICF, 2017). 


\section{Adolescent's knowledge on STI and HIV/AIDS}

In terms of percentage distribution of adolescents by knowledge on STIs and HIV/AIDS as per the 2016 NDHS, there was huge gap in the knowledge for the women of 10-14 and 15-19 years. Only 15.74 percent of adolescents of age 10-14 in comparison to 91.67 percent of the women of age 15-19 years who reported that they had heard about at least one STI. However, there was no significant gap in the knowledge about HIV/AIDS. Among the Gonorrhea and syphilis, syphilis was more heard than gonorrhea as in the chart.

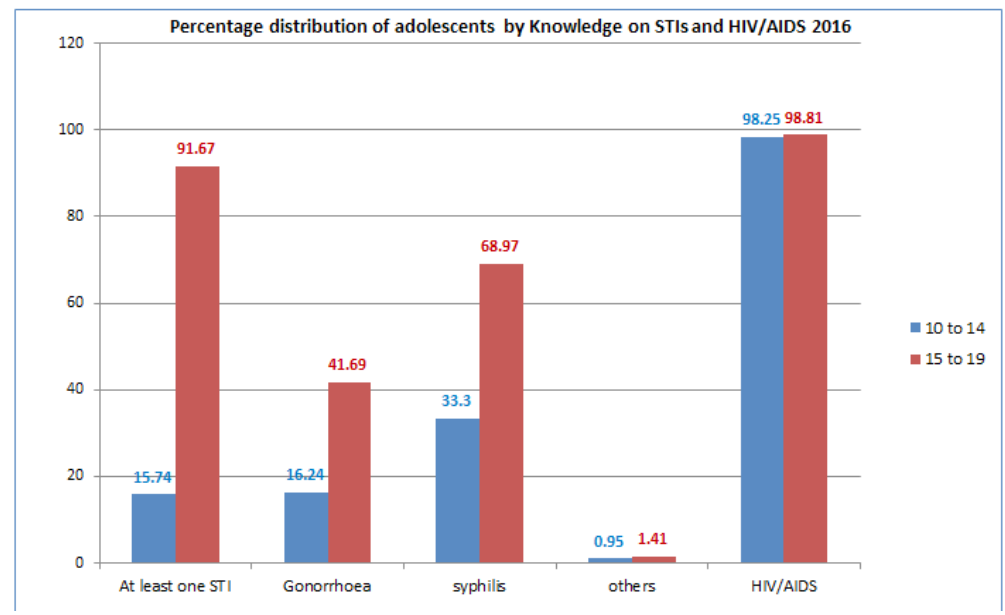

Source: 2016 NDHS

\section{Experience of physical violence by adolescents}

According to 2016 NDHS, among the women of age 15-49 who have ever experienced physical violence since age 15, about 10 percent were from age 15-19 years. Similarly, 7.2 percent respondents of age 15-19 reported that they had experienced physical violence often or sometimes in the past 12 months. Besides, among women age 15-49 who have ever been pregnant, 9 percent of women of age 15-19 years had experienced violence even during pregnancy. We can imagine the psychological state of those adolescents who often experience physical violence even during pregnancy (MOH, Nepal, New ERA \& ICF, 2017).

\section{Experience of sexual violence by adolescents}

Like physical violence, sexual violence had also been experienced by adolescent women according to 2016 NDHS. Among the women age 15-49 who have ever experienced sexual violence, 2.9 percent were adolescents of age 15-19 years. Similarly, 1.7 percent had experienced sexual violence in the 12 months preceding the survey (MOH, Nepal, New ERA \& ICF, 2017).

\section{Adolescents and HIV infection}

Based on data on 'cumulative HIV infection by age group and gender as of July 15, 2017' published by NCASC, there were total 18989 male, 11535 female and 122 transgender. In total, there were 30646 cases. Out of the total, 1.7 percent was from age 10-19 and three percent were of age 15-19. Though there were transgender small in number, 10 were of age 15-19 years (NCASC, 2017). 
Table 3: Cumulative HIV infections among adolescents by sex, July 2017

\begin{tabular}{|l|l|l|l|l|l|}
\hline Age & Male & Female & Transgender & Total & Percentage \\
\hline $10-14$ & 291 & 215 & 0 & 506 & 1.7 \\
\hline $15-19$ & 456 & 464 & 10 & 930 & 3.0 \\
\hline
\end{tabular}

Source: National Centre for AIDS and STD Control (NCASC), 2017

\section{Impact of marriage on adolescents}

Marriage is one of the major causes of drop out for girls. According to Nepal Adolescent and Youth Survey 2010/11 highlights, 2.19 percent female of 10-14 and 26.64 percent female of 15-19 years reported marriage as the cause of school dropout. For the same cause, 2.41 percent of male adolescents of age 15-19 mentioned marriage as the cause of dropout (in very low in comparison to female adolescents).

\section{Adolescent RH Policies in Nepal International documents on adolescent $\mathrm{RH}$}

International Conference on Population and Development(ICPD) 1994, Beijing Conference 1995 and their reviews, MDGs, and SDGs are some international documents that directly or indirectly guide the national policies and plans at national level. SDG has following goals related with adolescents and reproductive health (Lamichhane, 2019):

'5.3 Eliminate all harmful practices, such as child, early and forced marriage and female genital mutilation' and '5.6 Ensure universal access to sexual and reproductive health and reproductive rights as agreed in accordance with ICPD and the Beijing Platform for Action and the outcome documents of their review conferences'

On the basis of guidelines of ICPD Nepal has also prepared various plans, policies, and strategies in various time interval.

\section{National policies and programmes}

National Reproductive Health (RH) Strategy is one of the national policies regarding adolescent reproductive health. It identifies ARSH as one of the pillars of RH. Similarly, 2000 National Adolescent Health and Development Strategy has focused on (a) Empower adolescents with information and skills to protect themselves, (b) Targeted health services and counselling for adolescents and (c) Creating safe and supportive environments at various levels. As per the 2000 Essential Health Care Service (EHCS) Package, adolescent reproductive health services are a sub-set of reproductive health services. Similarly, National Health Communication Strategy for FP and MCH (2005-2010) focused adolescents as a target group. 2006 National AIDS strategy 2006 - 2011 has also considered adolescents and youth as the target groups. Besides, National Adolescent Development and Health Strategy 2075 (a revised version of National Adolesent health and Development adopted in 2018) has strategies to meet the ASRH needs with clear role of federal, provincial and local level governments. It has mentioned key interventoin area for improvement of sexual and reproductive health with nne startegic objectives (MOHP, 2018). 
Other adolescent RH related policies are

- Implementation Guide on Adolescent Sexual and Reproductive Health (2007)

- National Health Sector Program (NHSP) II (2010-2015): Target of introducing AFSs into 1000 public health facilities

- National ASRH communication Strategy (2011-2015)

- National Medical Standard-VoI I and II ASRH

- RH Clinical protocol-ASRH

- Three Year Plan (2011-13) strengthens NHSP-IP II (ARH, School health, Population management

- Fifteenth plan(Promote child/adolescent-friendly environment in school and other places)

- The Right to Safe Motherhood and Reproductive Health Act, 2075 (2018)

\section{Major Interventions Activities and Approaches}

There are various programs regarding adolescent reproductive health. Government of Nepal has adopted the following approaches: Strengthening national health system, peer education in school and community, family life education (facilitation), youth community mobilization, Information Education Communication (IEC)/Behavior Change Communication (BCC) regarding adolescent reproductive health, adolescent and youth friendly SRH service and Counseling, education and awareness (non/informal education, integrating with extracurricular activities).

\section{Gap/Challenges}

Government has various interventions as mentioned earlier. However, there are some gaps and challenges. Lack of uniformity in action of different actors, reporting/ data, lack of proper, IEC/ BCC, lack of inter/intra-sectoral coordination, no practicality of general counseling are some influencing factor for effective implementation of the interventions. Similarly, Comprehensive Sexuality Education (CSE) and 'School SRH' have not properly been addressed. Besides, there is the lack of adequate budget and trained personnel in school/university and community level. Finally, there is still lack of adolescent/youth-friendly services and facilities in terms of adolescent RH.

\section{Summary and Conclusions}

Adolescence is transitional period from childhood to adulthood; especially of 10-19 yrs. SRH is a state of complete physical, mental and social well-being in all matters relating to the reproductive system. Adolescent reproductive health is a healthy condition concerning the system, function and reproductive processes owned by a teenager. There are two paradigms on evolution of RH (1): The population control paradigm: From the 1954 Population Conference to the 1994 ICPD and (2) The Human Rights Paradigm ("Reproductive Rights Are Human Rights").

Median age at first marriage for female was 17.9 years and for male, it was 21.7 years. Similarly, age at first sexual intercourse for female was 17.9 years and for male it was 20.5 years. In Nepal, 17 percent of women age 15-19 had begun child bearing. ASFR for 15-19 years was 88 per 1000 women. CPR for 15-19 years women was 23.1 percent. Similarly, percentage of home delivery of adolescent women was 34.9 percent. Knowledge on legality of abortion was 42.1 percent. Among the female 15-19, 10.5 percent had experienced physical violence and 9.6 percent violence during pregnancy. 2.9 percent of the female 15-19 had experienced sexual violence. 
In order to meet the need of adolescent reproductive health service, the government should ensure that all ASRH program/activities are implemented as per National ASRH program implementation guide (as a minimum package) and led by MOHP. Exploring the ways to incorporate the age disaggregated indicators in HMIS needed for ASRH and improvement of record keeping should be done. Standard ASRH IEC/BCC materials should be produced and distributed to the respective schools and HPs. Updating of ARSH training package with current National Program, NHTC training ASRH package and ITGSE, prioritizing research agenda on ASRH issues and advocacy for continuing ASRH issues in school and universities is also necessary. Develop specific strategies for married and unmarried adolescents for reproductive health services. Adolescent/youth-friendly services and facilities are necessary to make their access.

\section{References}

Garbett, A., Perelli-Harris, B., \& Neal, S. (2021). The Untold Story of 50 Years of Adolescent Fertility in West Africa: A Cohort Perspective on the Quantum, Timing, and Spacing of Adolescent Childbearing. Population and Development Review, 47(1), 7-40.

IPPF.(2011). IPPF Charter on Sexual and Reproductive Rights Guidelineshttps://www.ippf.org/ resource/IPPF-Charter-Sexual-and-Reproductive-Rights

Lamichhane, K. (2019). Evolution of SRHR (MPhil lecture note, CDPS, TU).

Ministry of Health, Nepal, New ERA\& ICF. (2017).Nepal Demographic and Health Survey 2016. Kathmandu, Nepal: Author.

Ministry of Law, Justice and Parliament Affairs (2018). National Civil (Code) Act, 2017 (2074). Kathmandu: Author.

MOHP. (2011).Nepal Adolescent and Youth Survey 2010/11: Highlights https://nepal.unfpa.org/ sites/default/files/pub-pdf/NepalAdolescentandYouthSurveyHighlights\%282\%29.pdf

MOHP (2018). National Adolescent Development and Health Strategy 2075. Kathmandu: MOHP.

MOPE (2016). Nepal population report 2016. Retrieved from http://mope.gov.np/downloadfile/ Nepal\%20Population\%20Report\%202016_1481259851.pdf

NCASC (2017). Factsheet 2: Cumulative HIV/AIDS cases in Nepal July 2017. Retrieved from http://ncasc.gov.np/WAD2017/FACTSHEET-2017-FINAL/Factsheet-2-ReportedHIV-cases-2017.pdf

NCASC (2017).Cumulative HIV infection 2017. Kathmandu: NCASC.

Pandey, P.L., Seale, H. \& Razee, H. (2019). Exploring the factors impacting on access and acceptance of sexual and reproductive health services provided by adolescentfriendly health services in Nepal. PLOS ONE. DOI: https://doi.org/10.1371/journal. pone.0220855. Retrieved from https://journals.plos.org/plosone/article?id=10.1371/ journal.pone. 0220855

UNFPA (1998). Adolescent Reproductive Health: Making a Difference. Outlook.vol. 16, no.3,https://path.azureedge.net/media/documents/eol16_3.pdf

UNFPA (n.d). Sexual and reproductive health. Retrieved from https://www.unfpa.org/sexualreproductive-health 